\title{
A aventura de Deus na era dos simulacros e simulações: o real e o hiper-real em $O$ filho mais velho de Deus e/ou Livro IV, de Lourenço Mutarelli
}

Douglas Eraldo dos Santos ${ }^{\mathrm{i}}$

\section{RESUMO}

O presente trabalho parte das discussões de Jean Baudrillard, em Simulacros $e$ simulações (1991), e os conceitos de hiper-real e hiper-realismo, para propor uma leitura e interpretação do romance $O$ filho mais velho de Deus elou Livro IV (2018), de Lourenço Mutarelli

Palavras-chave: hiper-realismo; transcendentalismo; Deus; ateísmo; literatura brasileira.

\section{ABSTRACT}

This paperwork starts from Jean Baudrillard's discussions in Simulacros e simulações (1991) and the concepts of hyper-real and hyper-realism to propose an interpretation of the novel O filho mais velho de Deus elou Livro IV (2018), by Lourenço Mutarelli.

Keywords: hyper-realism; transcendentalism; God; atheism; Brazilian literature.

\footnotetext{
${ }^{\mathrm{i}}$ Licenciado em Letras e Respectivas Literaturas pela Universidade Federal de Pelotas - Ufpel e Mestrando em Letras pela Universidade de Santa Cruz do Sul - Unisc. Bolsista pela Coordenação de Aperfeiçoamento do Ensino Superior - Capes. O presente trabalho foi realizado com apoio da Coordenação de Aperfeiçoamento de Pessoal de Nível Superior - Brasil (CAPES) - Código de Financiamento 001.
} 
O homem que "aterrissou no JFK depois de um voo de duas horas e seis minutos como Albert Arthur Jones” (MUTARELLI, 2018, p. 13) cumpre o papel intermediário numa metamorfose que "apagará" seu passado enquanto Charles Noel Brown (o Peanuts) e uma ponte para seu futuro/presente como George Henry Lamsom. Esse homem, fragmentado em suas identidades e homonímias, deseja apenas deixar para trás sua vida mundana, adentrando numa estranha jornada (uma aventura) envolvendo "o governo, a Igreja e répteis" (MUTARELLI, 2018, p. 29), num emaranhado de teorias conspiratórias, Deus, demônios, alienígenas etc. Esse homem que também é três (que por si só evoca potenciais simbologias) é o protagonista de $O$ filho mais velho de Deus elou Livro IV ${ }^{1}$ de Lourenço Mutarelli, publicado pela Companhia das Letras em 2018. No romance, o espaço é ambientado em Nova York, onde:

Caso ressoasse a versão original [do tango Yira, yira] composta por Enrique Santos Discépolo e caso George falasse espanhol, Ele perceberia que a música servia como verdadeira trilha sonora para aquele momento. Nela Gardel diz: verás que tudo é mentira, verás que nada é amor. Que ao mundo nada the importa. Ele apenas gira, gira... (MUTARELLI, 2018, p. 51)

Tendo por trilha sonora um tango que evoca certo jogo de ilusões presente, é relevante neste trabalho observar em que cidade George/Albert/Charles desembarca enquanto busca uma nova vida e foge da sua antiga e envolve-se com uma inusitada instituição de proteção, a Cães Alados.

Vindo de Minneapolis, onde "ele estava vivendo sozinho num flat, já não tinha mulher ou amigos" e, "no fundo, como diria seu pai, sua vida vinha sendo bastante desnecessária” (MUTARELLI, 2018, p. 60), George/Albert/Charles chega "em Nova York [onde] o domingo parece dia de semana" (MUTARELLI, 2018, p. 60). Uma cidade que ele "parece não compreender. George parece ausente. George novamente se funde com a cidade. A cara de George Nova York, de tão contorcida, começa a escorrer" (MUTARELLI, 2018, p. 61), ambos transmutados simbioticamente numa tela surrealista de Salvador Dalí. Entretanto, a simbiose é efêmera, já que ele lembra de, "quando leu Fates Worse than Death", ter ignorado Kurt [Vonnegut] "mencionando o turco Yasar Kemal, ou pondo a palavra em sua boca [...] subitamente compreendi! Nova York pertencia a mim, tanto quanto a qualquer um, enquanto eu estava lá!" (MUTARELLI, 2018, p. 116). 
Nova York é para este estranho visitante uma metrópole que pisca, pisca, pisca; passageira, que lhe surge a despeito da jornada, mais pelas referências - um tango, uma canção de Simon \& Garfunkel - que por alguma experiência concreta, próxima, íntima. Uma cidade que, quando "começa a se tornar rotina", de certo modo, "sua cara fica menos caricata" (MUTARELLI, 2018, p. 135). Ainda assim, uma cidade-cenário, uma cidade impessoal onde "bebe coca [e o] lanche tem gosto de papelão na cidade-cenário" (MUTARELli, 2018, p. 107). Nova York, cidade-cenário onde ele se hospeda no Chelsa Savoy, cópia empobrecida de seu homônimo luxuoso. Nova York cidadecenário habitada por personagens sob a égide da homonímia. Só ele é três. Três homônimos. Aliás, quase todos no romance são homônimos (a destacar, ainda, que não meros homônimos, mas homônimos quase todos de assassinos, serial killers, elemento que talvez demande investigação distinta). A homonímia com sua ambiguidade, sua polissemia e, por que não, seu potencial de simulacro.

Assim, tal como os tradicionais souvenirs para turista comprar, a cidade-cenário trancafiada dentro de uma esfera de vidro (neste caso, a esfera é o romance), onde, em vez do famoso boneco de neve, eterno prisioneiro, George/Albert/Charles perambula ambiguamente entre o ceticismo e o existencialismo. Sua jornada talvez seja marcada pela força da era dos simulacros e simulações.

Neste sentido, o presente trabalho se propõe a debater o romance de Mutarelli na perspectiva das discussões de Jean Baudrillard acerca de Simulacros e simulação (1991). De acordo com o filósofo francês, "a histeria característica de nosso tempo: [é] a histeria da produção e da reprodução do real" (BAUDRILLARD, 1991, p. 33). Dos frutos nascentes dessa "histeria" - assim como Walter Benjamin, ao perceber por meio do Camundongo Mickey que "os filmes grotescos, dos Estados Unidos, e os filmes de Disney, produzem uma explosão terapêutica do inconsciente" (BENJAMIN, 1987, p. 190) - Baudrillard mostra o moto-perpétuo da Disneylândia enquanto exemplo de “imaginário a fim de fazer crer que o resto é real, quando toda Los Angeles e a América que a rodeia já não são reais, mas do domínio do hiper-real e da simulação" (BAUDRILLARD, 1991, p. 21). Para ele, “o imaginário da Disneylândia não é verdadeiro nem falso, é uma máquina de dissuasão encenada para regenerar, no plano oposto, a ficção do real" e lembrando que, "de resto, a Disneylândia não é caso único" (BAUDRILLARD, 1991, p. 21), conforme os diferentes exemplos trazidos em sua 
argumentação, a construir seu conceito de hiper-realidade, ou acontecimentos hiperreais:

\begin{abstract}
[acontecimentos] que já não têm exactamente conteúdo ou fins próprios, mas indefinidamente refractados uns pelos outros tal como os acontecimentos ditos como históricos: greves, manifestações, crises, etc. é nisto que são incontroláveis por uma ordem que só pode exercer-se sobre o real ou racional, sobre causas e fins, ordem referencial que só pode atuar sobre o referencial, poder determinado que só pode reinar num mundo determinado mas que nenhum poder exerce sobre esta recorrência indefinida da simulação, sobre esta nebulosa sem força de gravidade que já não obedece às leis da gravitação do real. (BAUDRILLARD, 1991, p. 32)
\end{abstract}

Assim, o hiper-real, portanto, é resultado dessa histeria de produção/reprodução do real, de modo que "o que toda uma sociedade, ao continuar a produzir e reproduzir, é ressuscitar o que lhes escapa" e "esta produção [material] é hoje, ela própria, o hiperreal". Por conseguinte, "o hiper-realismo da simulação traduz-se pela alucinante semelhança do real consigo próprio" (BAUDRILLARD, 1991, p. 34). Para Baudrillard, "os hiper-realistas fixam numa verossimilhança alucinante um real onde fugiu todo o sentido e todo o charme, toda a profundidade e a energia de representação" (BAUDRILLARD, 1991, p. 34).

Destarte, o hiper-real, em suma, é a "simulação [que] já não é mais simulação de um território, de um ser referencial, de uma substância, é a geração pelos modelos de um real sem origem nem realidade" (BAUDRILLARD, 1991, p. 8). Algo a que o autor se refere como "deserto do próprio real": 2

Já não se trata de imitação, nem de dobragem, nem mesmo de paródia. Tratase de uma substituição no real dos signos do real, isto é, de uma operação de dissuasão de todo o processo real pelo seu duplo operatório, máquina sinal ética metaestável, programática, impecável, que oferece todos os signos do real e lhes curto-circuita todas as peripécias. (BAUDRILLARD, 1991, p. 9)

Tais processos desempenharão mudanças significativas na irreferência divina das imagens, adentrando uma "querela milenária" em que se pergunta se "os simulacros que, só eles, ostentam o seu fausto e poder de fascinação - com o aparato visível dos ícones substituindo-se à Ideia pura e inteligível de Deus" (BAUDRILLARD, 1991, p. 11), de modo que, partindo dos medos e receios dos iconoclastas, 
[...] é precisamente porque estes apresentavam esta omnipotência dos simulacros, esta faculdade que têm de apagar Deus da consciência dos homens e esta verdade que deixam entrever, destruidora, aniquiladora, de que no fundo Deus nunca existiu, que nunca existiu nada senão o simulacro e mesmo que o próprio Deus nunca foi senão seu próprio simulacro. (BAUDRILLARD, 1991, p. 31-32)

Para Baudrillard teria sido mais tranquilo aos iconoclastas se acreditassem que isto ocultasse ou disfarçasse "a Ideia de Deus segundo Platão", pois "pode viver-se com a ideia de uma verdade alterada", entretanto "seu desespero metafísico provinha da ideia de que as imagens não escondiam nada, e de que, em suma, não eram imagens, mas de facto, simulacros". Neste caso, "é necessário conjurar a todo custo esta morte do referencial divino" (BAUDRILLARD, 1991, p. 32). Desta forma, entre

[...] a passagem dos signos que dissimulam alguma coisa aos signos que dissimulam que não há nada, marca a viragem decisiva. Os primeiros referem-se a uma teologia da verdade e do segredo (de que faz parte ainda a ideologia). Os segundos inauguram a era dos simulacros e da simulação, onde já não existe Deus para reconhecer os seus, onde já não existe juízo final para separar o falso do verdadeiro, o real da sua ressureição artificial, pois tudo está já antecipadamente morto e ressuscitado. (BAUDRILLARD, 1991, p. 14, grifos nossos)

Tendo tais questões prementes, nossa hipótese neste trabalho, como já dito, é de que talvez a narrativa de Lourenço Mutarelli esteja fortemente calcada nos dilemas, dramas e anseios regurgitados por tal era dos simulacros e da simulação; não somente por tudo que já tratamos aqui acerca dos elementos de simulacro e simulação constantes no romance, mas especialmente pelas teses acerca de Deus presente na obra e nas reflexões de seu protagonista George/Albert/Charles.

A "presença" de Deus e a relação acerca dele no romance já pode ser presumida a partir do próprio título do livro. Todavia, há de se considerar que o possível protagonismo de Deus no debate é diminuído, afinal, trata-se aparentemente do seu filho mais velho. No romance, esse filho mais velho serve para a exibição de uma lista quase que enciclopédica de demônios, entre eles, claro, Lúcifer, o mais velho para o narrador.

Embora haja certa relevância quanto "aos filhos de Deus" na narrativa, neste trabalho focaremos nele próprio, Deus, e como ele se apresenta ou não a seu protagonista. Nisso, antes de adentrarmos às questões religiosas de George/Albert/Charles, vale destacar novamente a proposta ambígua do romance. Um exemplo dessa ambiguidade é o próprio título aberto a duas possibilidades: "O filho 
mais velho de Deus e/ou Livro IV”. É curioso observar, ou mesmo questionarmo-nos, a que esta possibilidade alternativa - "e/ou Livro IV" - se refere. Numa narrativa de embate tão presente entre existencialismo, racionalismo e gnosticismo, é provável que não seja mera coincidência que IV seja também o ato (IV) de passagem famosa da peça Os justos, de Camus:

Kaliayev: Não é necessário dizer isso, irmão. Deus não pode nada. A justiça é questão nossa! (Um silêncio). Tu não compreendes? Tu conheces a lenda de São Dimitre?

Foka: Não.

Kaliayev: Ele tinha um encontro na estepe com o próprio Deus, e vinha apressado quando encontrou um camponês cuja carruagem estava atolada. Então, São Dimitre o ajudou. A lama era espessa, o atoleiro profundo. Foi necessário labutar durante uma hora. E quando aquilo acabou, São Dimitre correu para o encontro. Mas Deus não estava mais lá.

Foka: E aí?

Kaliayev: E aí há aqueles que chegarão sempre atrasados ao encontro porque há muitos irmãos a socorrer. (CAMUS apud ADAM, 2019, p. 130-131)

A passagem é emblemática e aberta a diferentes leituras e interpretações; aqui gostaríamos de chamar atenção para os pontos de contato com determinada passagem no romance de Mutarelli, quando o narrador do romance, como em grande parte deste, faz uma espécie de bricolagem, trazendo para dentro da obra recortes das mais variadas e distintas fontes. Nesse caso, a inserção de uma fábula de As mil e uma noites. Isto se dá por meio de um flashback em que George/Albert/Charles relembra da contação de sua tia Marie:

Na fábula, um mendigo entra no palácio do califa de Bagdá. O califa não estava no palácio naquele dia e os guardas mal notam a sua presença. $\mathrm{O}$ mendigo era tão insignificante que se tornou invisível. Ele entra e caminha até o trono e senta-se. [...] Nisso, um dos guardas, em choque, o percebe. Indignado com tal ousadia e com o gesto tão insólito, o guarda chama a atenção dos colegas e se aproxima do mendigo.

- Por acaso você sabe onde está?

- Sim. Eu sei - responde calmamente o mendigo.

Inconformado e incrédulo, o guarda o situa.

- Você está no palácio do califa.

- Eu sei.

- E, como se não bastasse, você está sentado no trono.

- Eu sei.

- E você sabe quem é o califa?

- Eu sei, e estou acima dele.

Desconcertado, o guarda continua:

- Você só pode ter perdido a inteligência por causa de sua miséria e pobreza. Por acaso você não sabe que acima do califa não existe senão o profeta Maomé? 
- Eu sei.

- E sabe quem é o profeta?

- Sei, e estou acima dele.

Os guardas, furiosos, apontam suas armas para o mendigo. O guarda que o interrogava pede calma e continua:

- Por acaso você não sabe que acima do profeta Maomé não existe ninguém senão Deus?

- Sei.

- E não sabe quem é Deus?

- Eu sei, e estou acima dele.

- Acima de Deus!? Você só pode estar louco! Acima de Deus nada existe!

- Eu sei. Eu sou justamente esse nada. (MUTARELLI, 2018, p. 110-111)

A despeito das mensagens e leituras que tais passagens podem levantar, não seria errôneo pensarmos que ambas, em algum modo/grau, declaram certa independência humana de Deus. Nos dois casos é a ação humana que está acima dos acontecimentos; que são os próprios acontecimentos. Talvez nelas o reconhecimento de Deus como ilusão; ou enquanto ausência.

No caso da fábula, recebendo a concordância do protagonista George/Albert/Charles: "e assim, sentado num banco no Madison Square Park, Nova York, nosso George fica acima de Deus" (MUTARELLI, 2018, p. 111). Claro que há de se considerar o ateísmo de George/Albert/Charles, descrença, inclusive, que the impossibilitou de participar dos Alcoólicos Anônimos, pois, "por não acreditar em Deus, não pôde entregar sua vontade e/ou vida a seus cuidados. Ele não concebia conceber Deus de nenhuma forma...” (MUTARELLI, 2018, p. 54). Seu suposto ateísmo será reforçado nas tentativas de desvencilhar-se do estranho grupo com quem se envolveu, Cães Alados. Sua tentativa de viver uma nova vida, mera aventura, lhe cobrará compromissos os quais aparentemente não está disposto a assumir: "Por que foi se meter com essa gente que acredita em seres do espaço, em reptilianos, discos voadores e Deus? E se não quiser seguir esse culto? E se quiser seguindo seus próprios pensamentos e acreditando em sua descrença?" (MUTARELLI, 2018, p. 144).

Por certo tempo, vale dizer, George/Albert/Charles se mantém resiliente em suas convicções descrentes. Em determinado momento diz a um dos integrantes da misteriosa organização:

- Sabe, Bennet, eu não vou me filiar a nenhum tipo de religião ou seita, meu velho. Eu não consigo acreditar em nenhum tipo de Deus. Posso até acreditar no mal. Sei que isso pode parecer contraditório, cara, mas, se eu tivesse que acreditar em algo, em algo sobrenatural e superior, eu só poderia acreditar no Diabo. (MUTARELLI, 2018, p. 143) 
Aliás, com a repetição de modo a enfatizar sua posição - “- Eu sei lá. É como... eu penso que o Diabo tem mais a ver com a gente, mas Deus? Deus não tem nada a ver com a gente" (MUTARELLI, 2018, p. 143) -, George/Albert/Charles acaba filiando-se a certa visão rosiana de que "o diabo vige dentro do homem, os crespos do homem" (ROSA, 1985, p. 10). Essa, por sinal, é uma questão a se investigar: certa tradição nacional e as razões que levam a certa prevalência da compreensão do Diabo sobre a de Deus em nossa literatura. Vemos essa desconfiança também quando Bernardo confessa “não, eu não acredito em Deus, mas acredito no Demônio" (CARDOSO, 1936, p. 134). Essa questão, contudo, deve ser tratada noutra oportunidade e requer, certamente, investigação mais ampla.

Por isso, voltemos à aventura de Deus nesse romance de Mutarelli e à veemência ateísta de seu protagonista, erigida, porém - veremos -, num ceticismo que não está livre das contradições e das complexidades que a discussão levanta. Isso porque o ceticismo ateísta do protagonista será abalado; e isso tem a ver não apenas com sua relação com a Cães Alados, mas pela proximidade de uma personagem que surge como voz questionadora de suas certezas: Sarah Simpsom/Trudi Stephens.

Sarah/Trudi - cujo segundo nome é homônimo ao de uma atriz pornô inglesa surge como uma espécie de guia de George/Albert/Charles no romance. Pertence à organização secreta e é posta junto a ele como forma de "abrir" seus olhos para a verdade sobre alienígenas que pretende pregar. Mas, acima de tudo, como uma guia também para questões espirituais e transcendentais. Aos poucos ela vai minando as barreiras de resistência de George/Albert/Charles. É com a aproximação a Sarah/Trudi que ele inicialmente vai tendo acesso aos estudos feitos por ela acerca dos demônios, o que, naquela técnica de bricolagem, faz brotar, como num verbete de enciclopédia, listas com diversos nomes de criaturas demoníacas de nossa cultura. Mas isso funciona quase como uma armadilha, fazendo com que ele se obrigue a pensar naquilo que rejeita, naquilo que não acredita de modo algum: Deus.

Então, a partir da construção de uma espécie de acerto de contas com a vida, uma autoavaliação de suas escolhas e caminhos, ao pensar no eterno, ele chega a “sentir, por um átimo, a presença de Deus" (MUTARELLI, 2018, p. 225). Até então, porém, resistente à ideia de Deus, se não plenamente, a resistência é rompida em certo 
grau, possibilitando que ele não apenas pense na questão, mas se detenha em teorizar sua visão particular sobre Deus. Isso se dá quando "George prova uma epifania brutal" (MUTARELLI, 2018, p. 230) e, num curioso debate sobre a natureza de Deus, em meio a um diálogo em que ele propõe e Sarah/Trudi problematiza, procura estabelecer sua argumentação em ideias talvez pós-modernas, que tentam unir a racionalidade da ciência e a espiritualidade transcendental, relacionando o big bang e Deus. Após relativa e longa explanação acerca da explosão cósmica que do nada fez surgir o universo, ele diz:

\begin{abstract}
Muito bem, Essa energia branca, que em função da explosão foi expelida para muito mais longe, sozinha e muito mais iluminada, seria, ou melhor, se tornaria, o que vocês chamam de Deus. [...]. Pois bem. Essa parte desse nada, ou seja lá o que for que estava lá aprisionado, se distancia e, quando mais ela avança, mais rápida ela se torna. E ela nunca mais poderá ser alcançada. Jamais! (MUTARELLI, 2018, p. 231-232)
\end{abstract}

Durante toda a conversa Sarah/Trudi mantém a postura problematizadora, expressando-se por frases curtas - "deixa ver se entendi...", “estou acompanhando" -, enquanto ele prossegue, tentando explicar sua concepção da entidade divina:

\footnotetext{
Essa partícula, energia ou coisa, quanto mais se distancia, mais acelera. Enquanto o resto, todo o resto, se torna cada vez mais lento e escuro... de qualquer forma isso que é muito mais lento e escuro do que aquilo que chamarei de Deus, cai. Enquanto aquilo que é Deus sobe. Sobe em direção oposta a nossa... (MUTARELLI, 2018, p. 232)
}

Vejamos que a concepção argumentada por George/Albert/Charles vem a dialogar com - e também justificar - a impossibilidade do encontro do homem com Deus, como vimos no trecho de Os justos e na fábula inserida no romance. A bem da verdade, é como se George/Albert/Charles encontrasse a resposta para tais desencontros. Para tanto, ele parte de uma reorientação de sua compreensão do infinito - "[...] nessa ideia que me ocorreu, o infinito era limitado. Deus em sua projeção, o expandiu e, segundo a teoria do big bang, continua aumentando sua infinitude" - para concluir que "continua e continuará aumentando e expandindo esse infinito" (MUTARELLI, 2018, p. 232).

Ainda que Sarah/Trudi quase se anime imaginando que ele tenha começado a entender Deus, George/Albert/Charles parte para a complementação de sua tese, 
rechaçando as intervenções de Sarah/Trudi: "enquanto ele [Deus] avança, mais ele se transforma. E nessa medida somos menos o que fomos. Deus já não tem nada a ver com a gente", diz George/Albert/Charles; "ele rompeu nosso conforto e continua avançando. Enquanto nós caímos. Nós e o resto de tudo que se tornou substância escura"; e, sob os olhares de uma Sarah/Trudi abobada, ele arremata: "a cada minuto Deus está mais diferente e distante do que somos" (MUTARELLI, 2018, p. 233). Mesmo que ela procure apontar as contradições e possíveis falhas da argumentação dele - "mas, então, o que você diz é que Deus existe" -, ele devolve: "talvez. Mas a cada instante ele tem menos relação conosco" (MUTARELLI, 2018, p. 233).

George/Albert/Charles retomará a questão com Sarah/Trudi após participar de cerimônia ritualística com o estranho grupo que une alienígenas e espiritualistas. Mantém-se convicto de que "quanto mais tempo eu der, menos sentido fará" (MUTARELLI, 2018, p. 242). Assim, numa segunda conversa com Sarah/Trudi, George/Albert/Charles, partindo de sua concepção de que apenas "somos vestígios de Deus" e de que este nada mais tem a ver conosco, tecerá as argumentações com as quais procura solidificar sua crença de por que o Diabo estaria mais próximo de nós que Deus: "o mal não está distante nem é tão diferente do que somos" e, enquanto o primeiro é matéria que foge cada vez mais na permanente expansão do infinito, o mal, tal como nós, matéria escura "precisa da gente. Não só porque tem a natureza semelhante à nossa", numa eterna procura "o mal precisa da gente. Para poder seguir Deus" (MUTARELLI, 2018, p. 249-50).

Sarah/Trudi procura contra-argumentar a partir das fragilidades e contradições do pensamento do protagonista, inclusive numa interpretação diferente da recorrente acerca do maniqueísmo, e na objeção à imagem do infinito de George/Albert/Charles como caminho de linha reta e plana: "não, George. Se você vislumbra o infinito dessa forma bidimensional, não faz ideia do que é o infinito" (MUTARELLI, 2018, p. 252). No entanto, ele começa a inviabilizar o debate: "é mais fácil pensar dessa forma, entende? Não quer dizer que penso o infinito assim...” (MUTARELLI, 2018, p. 253).

Nesse ponto, é curioso observar como o autor coloca seus personagens em campos opostos de uma luta que parece reproduzir e explicitar dramas internos e latentes. De um lado, George/Albert/Charles, por meio de seu ceticismo ateu, eleva a racionalidade pós-iluminista, em que Deus se esvai perante as descobertas da ciência; 
uma visão fria da existência humana, sem os refúgios da espiritualidade transcendental. Do outro lado a voz de Sarah/Trudi, que, na iminência de "perdê-lo", quase em tom de desespero, diz: "George, a vida tem que ser mais do que isso" (MUTARELLI, 2018, p. 257). Vejamos que há uma interferência mútua no discurso de ambos. Essa fala revela, em parte, o ceticismo dele sobre ela, enquanto o "talvez" dele revele, também, que ao menos ele tenta encontrar um meio de conceber Deus. Não o suficiente, contudo, para George/Albert/Charles se deixar convencer por Sarah/Trudi, pelos rituais da Cães Alados, ou mesmo pela existência de Deus.

Nada o convence. Tanto que ele decide abandonar a aventura e voltar para sua vida de sempre; e é aí que, curiosamente, a personagem morre pelas mãos do autor. $\mathrm{O}$ romance, então, age por sobre as convicções dele, através da insólita e transcendental experiência que será resumida no futuro, pela simples frase satírica: "e ele comeu o cu do ET" (MUTARELLI, 2018, p. 276).

Assim como a vida de George/Albert/Charles acaba dividida em três partes, o é o livro. Três partes que se subdividem na chegada à Nova York; depois certa maturação das discussões existenciais quando de sua proximidade a Sarah/Trudi e seus debates sobre Deus; e, por fim, a terceira parte pós-experiência transcendental - e gelatinosa com Sarah/Trudi em sua forma original, alienígena.

Isso acontece porque, na iminência do abandono dele ao grupo, ela se revela. É quando a obra adentra com os dois pés o maravilhoso, "algo que tem mais a ver com a natureza dos sonhos", algo em que "George, feito tonto, deixa o primeiro plano", numa experiência sexual gelatinosa e translúcida (e transcendental) com Sarah/Trudi (MUTARELLI, 2018, p. 271). Numa espécie de apostatação pelo sexo, George/Albert/Charles sucumbe à experiência imposta pelo romance/autor. Talvez numa mensagem de que, quem sabe, de fato entre o céu e a terra existam mais coisas do que possam supor nossas filosofias. Somos forçadamente transformados em leitoresHorácios ao final dessa segunda parte, quando o autor destrói as convicções de George/Albert/Charles.

Todavia, se pretender-se-ia isto como uma tomada de posição, a terceira parte da narrativa talvez embaralhe novamente as coisas, pois o acontecimento fantástico (transcendental) experimentado pelo protagonista atravessará a estética, até então 
predominante no romance, que a despeito das estranhezas e esquisitices, se mantinha com linearidade e verossimilhança.

A partir do final da segunda parte e sua experiência transcendental, contudo, o romance não só avança, salta e retrocede no tempo, como é marcado por extrema ebriedade, tanto da narração, como do protagonista, agora um bêbado a viver no Brasil e a contar suas peripécias sexuais com uma alienígena; tudo isso já sem a linearidade das duas primeiras partes. Nesse aspecto, com o caráter ébrio de seu desfecho, retomamos, talvez, a força dos anseios e dramas perpetrados aos sujeitos imersos nessa época dos hiper-realismos. Aliás, é interessante observar que, ainda que com definição ligeiramente distinta, o termo está presente no romance, como forma de identificar uma das experiências de George/Albert/Charles: "todos os sentidos se aguçam e fazem com que George sinta o que ele definirá um dia como hiper-realidade" e, "essa sensação o detém ali no parque. O faz passar um tempo observando tudo em detalhes nítidos e intensos" (MUTARELLI, 2018, p. 208). Experiência semelhante àquelas pelas quais passam, por exemplo, personagens de Philip K. Dick, reconhecido pelo caráter frágil que delega à realidade.

Numa outra oportunidade tratamos da possibilidade da interpretação multifacetada deste romance, estranhamente propício a múltiplas interpretações, a despeito de sua aparente frugalidade. Um romance que estaria mais próximo das narrativas de massa do que daqueles considerados de intenções literárias. Isso, entretanto, só demonstra a complexidade, não apenas dos estudos literários, mas também do respectivo romance. No caso deste artigo em específico, partindo das complexidades e contradições internas da obra, e especificamente do embate entre o racionalismo e o espiritualismo a partir das distintas visões apresentadas sobre Deus, chama-nos a atenção que o apagamento de tal referência divina parece exprimir e conter relações com a experiência pós-moderna que Baudrillard acabou chamando de "era dos simulacros e simulações".

O incômodo com o mundo parece latente nessa narrativa de Mutarelli. Um mundo erigido de simulações, como podemos observar nas cópias descaradas, nas homonímias, na construção do cenário como cenário. Os ecos de tais percepções incômodas parecem, portanto, encontrar vários exemplos, pois, assim como a 
Disneylândia, tudo parece ser construção na tentativa de convencer da realidade de algo que não está lá.

Então, ao tomarmos consciência dessa ausência, desnuda-se o tormento que se exalta nas vozes distintas desta narrativa até seu desfecho bêbado; e quem sabe, revelase a amargura provocada pela compreensão de que se trata apenas de nós, como a piadametáfora de George a um companheiro (lagarto) de copo:

- Um humano olha para um lago escuro. É o lago da sabedoria e ele sabe disso. Ele busca aquilo que está no fundo. Então ele se agacha para espreitar de mais perto. Ao fazer isso, ele acaba vendo seu reflexo na água. Então ele penteia o cabelo.

- E...?

- É isso. Ele penteia o cabelo e vai embora. (MUTARELLI, 2018, p. 324325)

\section{Referências}

BENJAMIN, Walter. Magia e técnica, arte e política. São Paulo: Brasiliense, 1987.

BAUDRILLARD, Jean. Simulacros e simulação. Lisboa: Relógio D’Água, 1991.

CAMUS, Albert. Os justos, Ato IV. In: ADAM, Jean-Michel. Textos, tipos e protótipos. São Paulo: Contexto, 2019.

CARDOSO, Lúcio. A luz do subsolo. Rio de Janeiro: José Olympio, 1936.

MUTARELLI, Lourenço. O filho mais velho de Deus elou Livro VI. Rio de Janeiro: Companhia das Letras, 2018.

ROSA, Guimarães. Grande sertão: veredas. São Paulo: Nova Cultural, 1985.

Recebido em: 21/07/2020

Aceito em: 19/09/2020

\footnotetext{
${ }^{1} \mathrm{O}$ romance foi publicado sob encomenda no contexto da Coleção Amores Expressos, cuja proposta foi a de enviar diferentes autores a diferentes cidades do mundo, para que, depois da experiência, escrevessem uma trama de amor na cidade visitada. Nova York, no caso desta obra, encontrou certa rejeição do autor. Além disso, vale destacar que, nesse caso específico, o resultado é a segunda tentativa do autor, pois Mutarelli jogou no lixo a primeira proposta, que fora recusada também pelos editores.
}

${ }^{2}$ A expressão desempenhará forte influência na narrativa cinematográfica cyberpunk Matrix (1999). 